\title{
Electrochemical Oxidation of Aqueous Sulfur Dioxide II. Comparative Studies on Platinum and Gold Electrodes
}

(4ts)

\author{
J. A. O'Brien, ${ }^{a, b}$ J. T. Hinkley, ${ }^{a}$ and S. W. Donne ${ }^{b, *, z}$ \\ ${ }^{a}$ CSIRO Energy Technology, Newcastle, NSW 2300, Australia \\ ${ }^{b}$ Discipline of Chemistry, University of Newcastle, Callaghan, NSW 2308, Australia
}

\begin{abstract}
The reaction pathway of sulfur dioxide electro-oxidation on platinum and gold substrates is investigated here using a combination of static and rotating electrode voltammetric methods. A gold electrocatalyst does not need to be sulfur modified in order to display high activity, meaning the substrate is inherently more active than platinum. Analysis of diffusion behavior and reaction order on these substrates suggests that both kinetic and diffusion limitations control oxidation on each electrode. However, it is proposed that a similar oxidation pathway, involving adsorption and subsequent oxidation of sulfur dioxide on the electrode surface, is followed for an activated electrode. Mass changes were monitored at the electrode surface using an electrochemical quartz crystal microbalance, and both in- and ex-situ observations support this pathway proposal. (C) 2012 The Electrochemical Society. [DOI: 10.1149/2.060209jes] All rights reserved.
\end{abstract}

Manuscript submitted April 23, 2012; revised manuscript received June 29, 2012. Published August 14, 2012.

Sulfur dioxide electrochemistry has been an area of widely varied research interest over the last few decades. The reaction has been of interest most recently due to its poisoning effect on the oxygen reduction reaction in fuel cells. ${ }^{1}$ The electrochemical oxidation of sulfur dioxide is also of great relevance to the hybrid sulfur (HyS) cycle, a water splitting cycle for large scale hydrogen production. The greatest advantage the HyS cycle has over conventional electrolysis is the reduction in the required electrical input through the use of sulfur intermediates. Hydrogen and oxygen evolution steps are split into electrical and thermal components, respectively, and both energy inputs can be supplied using solar sources. ${ }^{2}$ Hydrogen is evolved as the cathodic reaction of an acid electrolyser, while, sulfur dioxide is oxidized to sulfuric acid in the anodic compartment; i.e.,

$$
\begin{gathered}
2 \mathrm{H}^{+}+2 \mathrm{e}^{-} \rightarrow \mathrm{H}_{2}(\mathrm{~g}) \quad \mathrm{E}^{\mathrm{o}}=0.000 \mathrm{~V} \\
\mathrm{SO}_{2}(\mathrm{aq})+2 \mathrm{H}_{2} \mathrm{O} \rightarrow \mathrm{H}_{2} \mathrm{SO}_{4}(\mathrm{aq})+2 \mathrm{H}^{+}+2 \mathrm{e}^{-} \quad \mathrm{E}^{\mathrm{o}}=0.157 \mathrm{~V}
\end{gathered}
$$

$$
\mathrm{SO}_{2}(\mathrm{aq})+2 \mathrm{H}_{2} \mathrm{O} \rightarrow \mathrm{H}_{2} \mathrm{SO}_{4}(\mathrm{aq})+\mathrm{H}_{2}(\mathrm{~g}) \quad \mathrm{E}^{\mathrm{o}}=0.157 \mathrm{~V}
$$

The evolution of hydrogen (Eqn. 1) occurs with an onset close to thermodynamic predictions. However, the anodic oxidation of sulfur dioxide, has been shown to have an onset far above thermodynamic predictions, showing clear kinetic limitations and variable catalytic activity depending on the electrode substrate. ${ }^{3}$ Catalyst development for this reaction has previously been limited to screening of mostly noble metals and some transition metal alloys. ${ }^{4}$ However, the complexity of the reaction, and its sensitivity to surface preconditioning, ${ }^{5}$ suggests an active catalyst may best be found through mechanistic understanding of the reaction.

The electrochemical oxidation of sulfur dioxide has been studied extensively on platinum electrodes..$^{5-9}$ The performance on platinum has been intrinsically linked to sulfur formation at the electrode surface at potentials less than $0.45 \mathrm{~V}$. This is due to the reduction of sulfur dioxide to sulfur according to: ${ }^{10}$

$$
\mathrm{SO}_{2}(\mathrm{aq})+4 \mathrm{H}^{+}+4 \mathrm{e}^{-} \rightarrow \mathrm{S}(\mathrm{s})+2 \mathrm{H}_{2} \mathrm{O} \quad \mathrm{E}^{\circ}=0.449 \mathrm{~V}
$$

Activity varies between limited, catalytic or inhibited oxidation depending on the sulfur coverage, as outlined in Part I of our work. ${ }^{5} \mathrm{~A}$ significant drop in achievable current density was observed as the acid concentration was increased,${ }^{5}$ although this effect was not a result of excessive sulfur formation but due to another limiting factor. It was proposed that this limitation was caused by a drop in the activity of sulfur dioxide in more concentrated solutions. ${ }^{5}$ The greatest catalytic

*Electrochemical Society Active Member.

${ }^{\mathrm{z}}$ E-mail: Scott.Donne@newcastle.edu.au activity was observed to occur on platinum with approximately a bilayer of sulfur coverage, ${ }^{5,11}$ suggesting the electrode is completely covered with sulfur for best activity. Recently, this catalytic oxidation scenario was observed to show further inherent complexity due to an electrochemical oscillation in the oxidation current observed both over time and with changing potential. ${ }^{12}$ This was classified as an electrochemical oscillation, and it was discussed that the most likely pathway for this mechanism involved the limiting intermediate formation of dithionate $\left(\mathrm{S}_{2} \mathrm{O}_{6}{ }^{2-}\right)$. Dithionate formation explains in part the poor oxidation kinetics of the oxidation reaction, although the reason for the oxidation overpotential is still unclear.

It has been proposed in the literature that adsorption strength of gaseous sulfur dioxide onto gold and platinum electrodes is very different. ${ }^{11,12}$ In the current study, the oxidation reaction on gold and platinum will be compared in order to elucidate further information regarding the role of the electrode surface and subsequent catalysis specifically related to the adsorption of sulfur dioxide. Aqueous sulfur dioxide solutions will also be studied on a gold electrode to determine the effect of acid concentration on the sulfur dioxide diffusion coefficient.

\section{Experimental}

Solutions. - Acidic solutions were prepared from concentrated sulfuric acid (99 wt $\% \mathrm{H}_{2} \mathrm{SO}_{4}$, Scharlau). Stock sodium sulfite solution was prepared from its crystalline form (Ajax Fine Chemicals, minimum $98 \% \mathrm{Na}_{2} \mathrm{SO}_{3}$ assay) and spiked into acidic solutions to ensure controlled sulfur dioxide concentrations. Acidic solutions were purged with nitrogen for 10 minutes prior to sulfite addition; however, stock sulfite solutions were not purged and may contain some dissolved oxygen. All aqueous solutions were prepared using ultrapure water supplied through a Milli-Q water system (>18.2 M $\Omega$ resistivity).

Saturated sulfur dioxide solutions were prepared by introducing sulfur dioxide gas (BOC Gases) from a gas cylinder under $500 \mathrm{kPa}$ through a safety container before introducing to the working solution through a porous glass frit. Saturation was achieved after 20 minutes, while a small sulfur dioxide flow continued during the electrochemical experiments to ensure saturation was maintained.

Electrochemical overview.- A three electrode electrochemical cell was used for experiments. Polycrystalline platinum and gold working electrodes of $5 \mathrm{~mm}$ diameter were used as received from Pine Instruments in the E4 series quick change electrode holder. The active surface area of both electrode type types was measured using the well known $\left[\mathrm{Fe}(\mathrm{CN})_{6}\right]^{3-/ 4-}$ system and electrochemical modeling. ${ }^{13}$ The surface area of the platinum electrode was also determined using the hydrogen desorption charge $(0.05<\mathrm{E}$ $<0.4 \mathrm{~V}$ vs. SHE). ${ }^{14}$ Since the electrodes were purchased with a mirror 
finish, a low surface roughness $\left(\mathrm{R}_{\mathrm{S}}\right)$ was expected. A surface area of $0.2 \mathrm{~cm}^{2}$, giving $\mathrm{R}_{\mathrm{S}}=\mathrm{A}_{\mathrm{REAL}} / \mathrm{A}_{\mathrm{GEO}}=1.02$, was used for all electrodes to determine the current density. Electrode cleaning procedures have been outlined before [5], and were used for both the platinum and gold substrates. The counter electrode consisted of a small platinum sheet $\left(\sim 1 \mathrm{~cm}^{2}\right)$ wrapped around platinum wire, wound in a spiral and separated from the main solution by a glass frit. The reference electrode was a double junction saturated $\mathrm{Ag} / \mathrm{AgCl}$ reference electrode. All potentials reported herein have been adjusted to the SHE. To ensure consistent sulfur formation at the electrode surface, the same electrode pre-treatment procedure, described in Reference, ${ }^{12}$ was used (unless otherwise specified). This consisted of sulfur layer formation of the sulfur layer in a $1 \mathrm{M} \mathrm{H}_{2} \mathrm{SO}_{4}+100 \mathrm{mM} \mathrm{SO}_{2}$ solution, followed by a slow cyclic sweep in the same solution at $5 \mathrm{mV} \mathrm{s}^{-1}$. The electrode was then removed, rinsed with ultra pure Milli-Q water, and placed into the solution of interest. All solution preparation and electrochemical experimentation was conducted at $22 \pm 1{ }^{\circ} \mathrm{C}$.

Electrochemical quartz crystal microbalance (EQCM).- The quartz crystal microbalance used was a Stanford Research Systems (SRS) QCM200. This was interfaced with an Autolab potentiostat and outputs were monitored through Nova software. The input potential was applied to the electrochemical probe and crystal holder. Platinum and gold coated $5 \mathrm{MHz}$ AT-cut quartz crystals (SRS) were used as working electrodes, and the electrode area was determined using hydrogen desorption charge on platinum $\left(\mathrm{A}_{\mathrm{ACTUAL}}=7.8 \mathrm{~cm}^{2}\right.$ compared to $\left.\mathrm{A}_{\mathrm{GEO}}=1.4 \mathrm{~cm}^{2}, \mathrm{R}_{\mathrm{S}}=5.6\right)$. Calibration of the crystals for the specific frequency response with mass change was carried out using copper deposition, where an average frequency for the quartz of $37.55 \mathrm{~Hz} \mu \mathrm{g}^{-1}$ was determined. A small difference in this value was observed between different quartz disks $( \pm 5 \%)$. This value was used for all mass normalisations according to the Sauerbrey equation; i.e.,

$$
\Delta \mathrm{f}=-\mathrm{C}_{\mathrm{f}} \times \Delta \mathrm{m}
$$

where $\Delta \mathrm{f}$ is the frequency change $(\mathrm{Hz}), \Delta \mathrm{m}$ the mass change $(\mu \mathrm{g})$, and

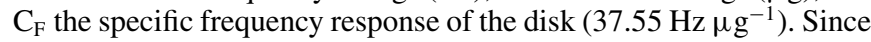
copper at the electrode surface needed to be avoided due to possible mechanistic effects or spurious mass influences due to dissolution, only fresh electrodes were used for the electrochemical experiments.

The mass was zeroed manually where appropriate; however, it should be emphasized that this value is a relative number and should not be taken as absolute zero. On clean platinum and gold electrodes, cyclic voltammograms were obtained. Due to larger than normal resistance measured between the working and reference electrodes, $\mathrm{i}-\mathrm{R}$ compensation was employed. The uncompensated resistance $\left(R_{U}\right)$ was determined using the current interrupt method ${ }^{12}$ (without i-R compensation strong resistance limitations were observed).

\section{Results and Discussion}

Sulfur catalysis on platinum versus gold.- Sulfur formation on a platinum electrode has a significant effect on the activity of the electrode, and has been has been observed to shift both oxidation peaks and onsets in several studies. ${ }^{3,5}$ Sulfur is formed in sulfur dioxide solutions as shown in Eqn. 4, a four electron reduction reaction. In Figures $1 \mathrm{a}$ and $1 \mathrm{~b}$, the effect of sulfur coverage on the current response on platinum and gold is shown as a function of the lower potential limit ( $\mathrm{E}_{\text {low }} ; 2$ min hold time). Figures $1 \mathrm{c}$ and $1 \mathrm{~d}$ show the onset potential determined from the subsequent anodic sweep immediately following potential holding.

It can be seen in Figures 1e and 1f that less sulfur is formed on a gold electrode compared to platinum for the same lower potential limit; however, sulfur formed on gold does not affect the catalytic oxidation of sulfur dioxide as strongly as observed on platinum. The onset potential for both surfaces, shown in Figures 1c and 1d, was found using a Tafel plot (overpotential versus $\log (\mathrm{i})$ ) to determine the $\mathrm{X}$-axis intercept. For oxidation on gold this is not the main onset potential for oxidation since a small pre-wave was observed, which has not been previously identified. In this case, the point at which
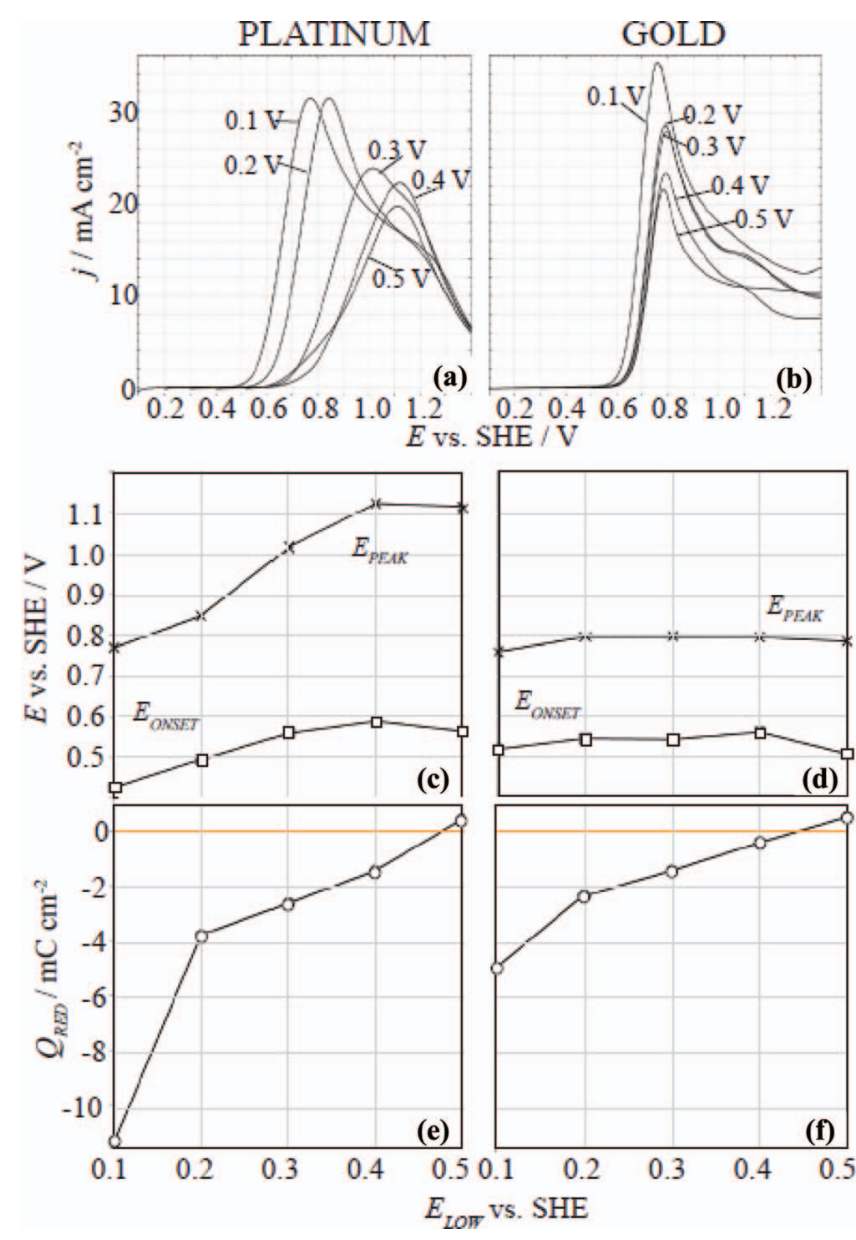

Figure 1. Sulfur formation and effects on platinum and gold. $1 \mathrm{M} \mathrm{H}_{2} \mathrm{SO}_{4}$, $100 \mathrm{mM} \mathrm{SO}_{2}, 1 \mathrm{~V} \mathrm{~s}^{-1}$. (a) Platinum and (b) gold voltammetry (forward sweep only shown), $\mathrm{E}_{\text {low }}$ indicated in figure; (c) platinum and (d) gold resultant peak and onset potentials corresponding to (a) and (b); (e) platinum and (f) gold reductive charge passed while holding at specified $\mathrm{E}_{\text {low }}$ for 2 minutes.

the Tafel region for the main oxidation begins has been taken as the onset. An example of the Tafel plot used to determine oxidation onset potential for gold and platinum is shown in Figure 2, for $\mathrm{E}_{\text {low }}=0.4 \mathrm{~V}$, with an equilibrium potential of $0.193 \mathrm{~V}$ calculated from the Nernst equation for Eqn. 2 and the electrolyte conditions enabling calculation of the overpotential.

For platinum, the onset potential $\left(\mathrm{E}_{\text {onset }}\right)$ and peak potential $\left(\mathrm{E}_{\text {peak }}\right)$ both decrease to more cathodic potentials as $\mathrm{E}_{\text {low }}$ was decreased, indicating a marked improvement in performance with sulfur coverage. However, gold is not similarly affected, with a small improvement in peak current and $E_{\text {onset }}$ after alteration with sulfur coverage. This demonstrates a difference in the catalytic effect of sulfur on different electrode substrates, as well as the inherent activity (noted previously) of a gold substrate which does not need to be sulfur modified to show high activity.

Sulfur dioxide diffusion coefficient.-The diffusion coefficient of sulfur dioxide has been estimated in the literature to be 2.0 $\times 10^{-5} \mathrm{~cm}^{2} \mathrm{~s}^{-1}$ and $1.8 \times 10^{-5} \mathrm{~cm}^{2} \mathrm{~s}^{-1}$, determined using platinum ${ }^{8}$ and gold ${ }^{15}$ electrodes, respectively. Both values were measured in $0.1-0.5 \mathrm{M} \mathrm{H}_{2} \mathrm{SO}_{4}$ over a wide range of sulfur dioxide concentrations. It is possible, considering the influence of concentrated sulfuric acid solutions on the overall electrode reaction kinetics, ${ }^{5}$ that the diffusion of sulfur dioxide is hampered in concentrated solutions. 


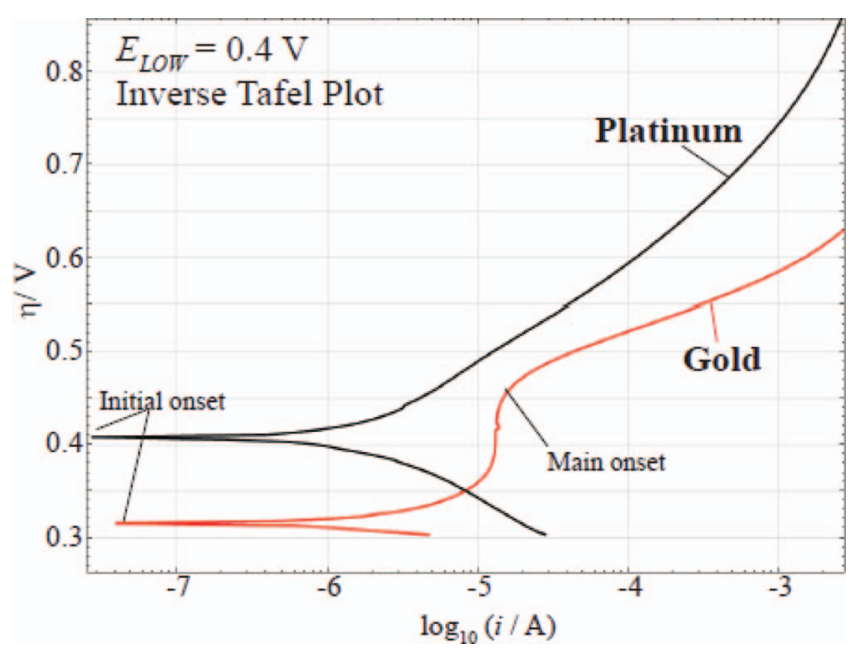

Figure 2. Inverse Tafel plot for the onset of oxidation on platinum and gold. $1 \mathrm{M} \mathrm{H}_{2} \mathrm{SO}_{4}, 100 \mathrm{mM} \mathrm{SO}_{2}, 1 \mathrm{~V} \mathrm{~s}^{-1}, \mathrm{E}_{\text {low }}=0.4 \mathrm{~V}$.

In this work diffusion coefficients were determined using the Levich equation; i.e.,

$$
\mathrm{j}_{\text {lim }}=0.62 \mathrm{n}_{\mathrm{a}} \operatorname{FAD}_{i}^{2 / 3} \nu^{-1 / 6} \omega^{1 / 2} \mathrm{c}_{i}
$$

where, $\mathrm{j}_{\text {lim }}$ is the limiting current density, $\mathrm{n}_{\mathrm{a}}$ is the number of electrons involved in the anodic oxidation reaction, and $\mathrm{A}$ is the active electrode area. $D_{i}$ and $c_{i}$ are the diffusion coefficient and concentration of species $i$, respectively, with $\nu$ representing kinematic viscosity, and $\omega$ the electrode rotation rate $\left(\mathrm{rad} \mathrm{s}^{-1}\right)$. The first oxidation peak on both platinum and gold has been previously identified as being diffusion controlled $^{8,15}$ using coulometric and RDE techniques. However, if we compare RDE data for both electrode materials (sulfur modified for highest highest activity; i.e., $\mathrm{E}_{\text {low }}=0.15 \mathrm{~V}$ on both electrodes) as shown in Figure 3, it can be seen that platinum does not reach diffusion limited conditions, becoming inhibited at $\mathrm{E}>0.9 \mathrm{~V}$.

Gold shows a clear diffusion plateau. This is confirmed when the diffusion limited current (values taken at $\mathrm{E}=1.0 \mathrm{~V}$ vs. SHE for platinum) as shown in Figure 3c. A linear response with zero intercept is observed for gold, while the response for platinum is curved - indicating the contribution of a kinetic component. The slope calculated

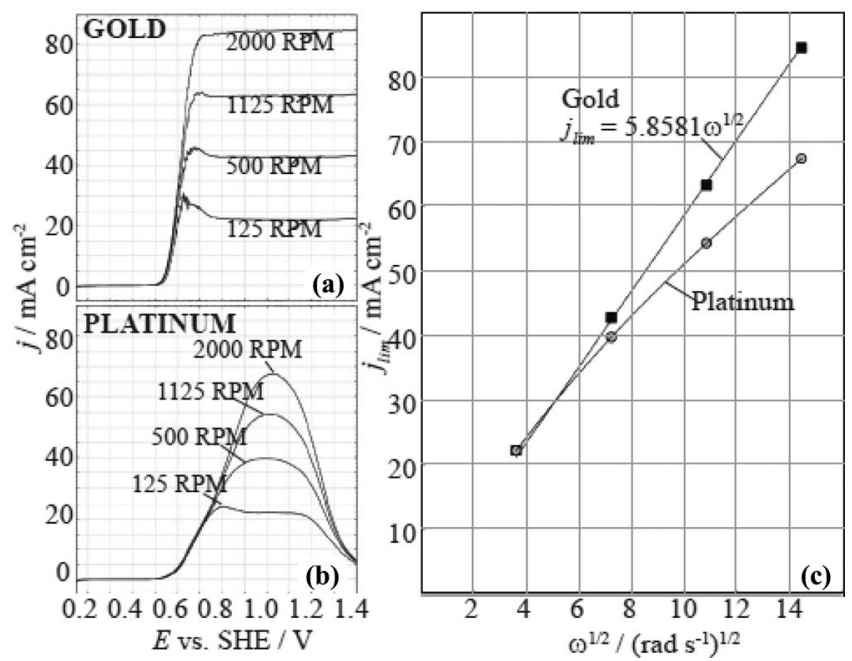

Figure 3. RDE behavior of platinum and gold. (a) Platinum and (b) gold in $1 \mathrm{M} \mathrm{H}_{2} \mathrm{SO}_{4}, 50 \mathrm{mM} \mathrm{SO}_{2}, 50 \mathrm{mV} \mathrm{s}^{-1}, \mathrm{E}_{\text {low }}=0.15 \mathrm{~V}$, twait $(\mathrm{OCP})=10 \mathrm{~s}$, rotation rate indicated in figure; (c) peak current versus square root of the rotation rate from data shown in (a) and (b). Temperature $=22 \pm 1{ }^{\circ} \mathrm{C}$.

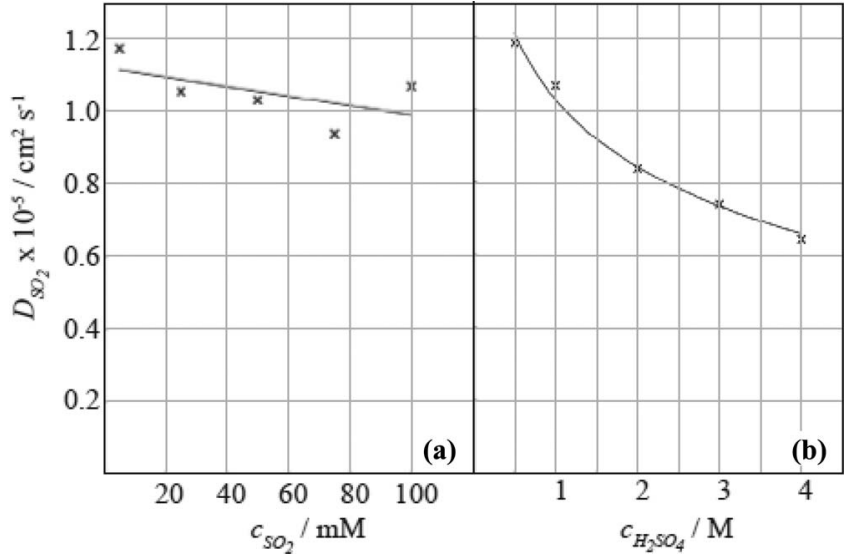

Figure 4. Sulfur dioxide diffusion coefficient determined on a gold electrode. (a) Effect of sulfur dioxide concentration $\left(1 \mathrm{M} \mathrm{H}_{2} \mathrm{SO}_{4}\right)$. (b) Effect of sulfuric acid concentration $\left(100 \mathrm{mM} \mathrm{SO}_{2}\right)$.

for oxidation on a gold electrode was used to determine the diffusion coefficient as $1.03 \times 10^{-5} \mathrm{~cm}^{2} \mathrm{~s}^{-1}$, which is significantly smaller than observed in the literature, ${ }^{8,15}$ using the kinematic viscosity for $1 \mathrm{M}$ $\mathrm{H}_{2} \mathrm{SO}_{4} \cdot{ }^{16}$

Results indicate that the sulfur dioxide concentration in the range of $10-100 \mathrm{mM}$ has a minor effect on the diffusion coefficient in $1 \mathrm{M} \mathrm{H}_{2} \mathrm{SO}_{4}$, with a small decrease observed as the sulfur dioxide concentration increased, as shown in Figure 4.

When the sulfuric acid concentration is increased, a marked decrease in the diffusion coefficient can be clearly seen. Beyond a sulfuric acid concentration of $4 \mathrm{M}$, the oxidation on gold becomes kinetically limited and the diffusion coefficient can no longer be determined using this method. This decrease is not a result of changes in the solution viscosity, as this is already accounted for in Eqn. 6. A drop in the measured diffusion coefficient with an increasing supporting electrolyte concentration is a common phenomenon; ${ }^{17}$ e.g., the diffusion coefficient of $\mathrm{Fe}(\mathrm{CN})_{6}{ }^{3-}$ decreases roughly linearly from 0.765 $\times 10^{-5} \mathrm{~cm}^{2} / \mathrm{s}$ in $0.05 \mathrm{M} \mathrm{KCl}$ to $0.739 \times 10^{-5} \mathrm{~cm}^{2} / \mathrm{s}$ in $3.0 \mathrm{M} \mathrm{KCl}$. In this example, where the decrease in diffusion coefficient is relatively small, it is expected that there will be little if any chemical interaction between the analyte and supporting electrolyte, as opposed to electrostatic interaction which may be significant. However, the extent of the decrease in diffusion coefficient observed in the work presented here indicates the possibility of significant chemical interaction between the sulfur-oxide solution species; i.e., $\mathrm{SO}_{2}-\mathrm{SO}_{4}{ }^{2-}$ interactions.

Reaction order data.-The reaction order with respect to sulfur dioxide has been found to vary in the literature on different electrode surfaces between values of 0.5 and $2 .{ }^{3}$ This variation is most likely due to the fact that the oxidation mechanism varies markedly on modified and unmodified platinum electrode ${ }^{5}$ which may affect reaction order. The reaction order has also been determined on gold; however, only a small range of concentrations $(1-6 \mathrm{mM})$ was investigated. ${ }^{15}$ Here, the reaction order will be determined on both platinum and gold electrodes for a catalytically activated scenario; i.e., held at $\mathrm{E}_{\text {low }}$ $=0.15 \mathrm{~V}$ for 2 minutes for a $\mathrm{SO}_{2}$ concentration range of 25-100 $\mathrm{mM}$ using a rotating electrode at $500 \mathrm{rpm}$. The method used involves firstly determining the potential region under which the oxidation is kinetically limited. This can be determined from RDE data as the potential region where the current density (j) is unchanging with rotation speed. It can be seen in Figure 3 that both platinum and gold have a kinetically limited region below $\sim 0.65 \mathrm{~V}$ for a $50 \mathrm{mM} \mathrm{SO}_{2}$ solution (no change in oxidation current with rotation rate). To find the reaction order with respect to sulfur dioxide, the concentration needs to be varied while holding all other variables constant. The reaction order can then be found using:

$$
\log (\mathrm{j})=\text { constant }+\mathrm{r}_{\mathrm{SO}_{2}} \log \left(\mathrm{c}_{\mathrm{SO}_{2}}\right)
$$



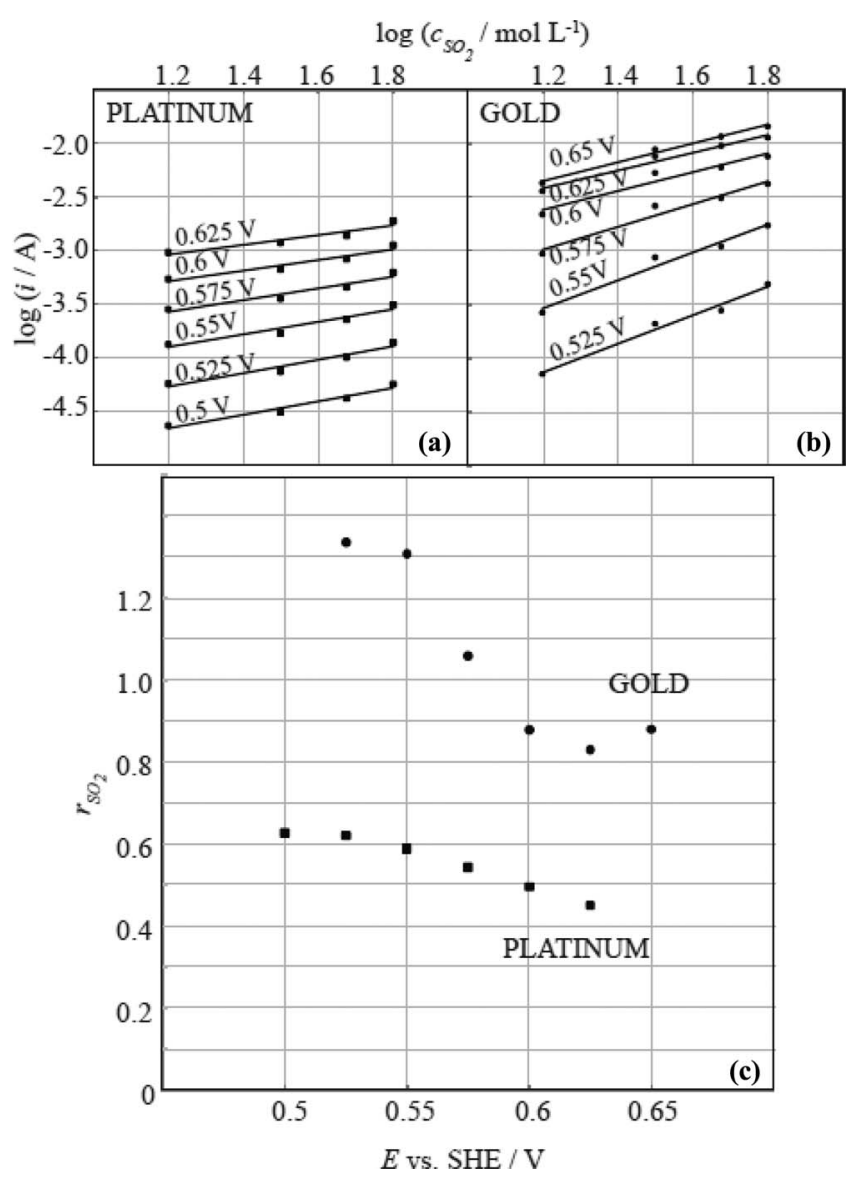

Figure 5. Reaction order slopes for (a) platinum and (b) gold with (c) comparison of calculated reaction order.

where $\mathrm{r}_{\mathrm{SO}_{2}}$ is the reaction order. Plotting $\log (j)$ versus $\log \left(\mathrm{c}_{\mathrm{SO}_{2}}\right)$ leads to the results for platinum and gold shown in Figure 5. Note that for the gold electrode the relatively slight increase in $\log (i)$ when the potential was increased from 0.625 to $0.65 \mathrm{~V}$ is most likely due to the influence of mass transport limitations at these higher potentials. Nevertheless, it can be seen that the reaction order is significantly different for platinum and gold. Variation is observed with potential for both platinum and gold, although changes are more significant on gold. The change in reaction order is indicative of a change in reaction mechanism as the potential region shifts. This may be a result of the pre-oxidation peak observed at low potentials prior to the main onset potential, as noted from Figure 2. A pre-oxidation peak on gold has been previously observed, although this occurred only after cycling to very negative potentials - this peak is believed to be due to the oxidation of $\mathrm{H}_{2} \mathrm{~S}$ species. ${ }^{10}$ In our case, the potential has not gone low enough to have formed $\mathrm{H}_{2} \mathrm{~S}$. Therefore, this pre-peak is most likely due to oxidation of sulfur dioxide through a different pathway to the main peak - which would account for the change in reaction order as the main oxidation begins. The reaction order on platinum is consistently less than 1 and values are within the range of those observed in the literature, generally between 0.5 and 1 .

Oscillatory behavior-An extensive investigation of observed electrochemical oscillations on sulfur modified platinum has been reported previously. ${ }^{12}$ The oscillation was not observed on an unmodified platinum substrate $\left(\mathrm{E}_{\text {low }}>\mathrm{OCP}\right.$, which was typically $\sim 0.45 \mathrm{~V}$ vs $\mathrm{SHE}$ ), suggesting the oscillation, and thus the dual pathway mechanism proposed, is substrate sensitive. The same procedure that was used to investigate oscillations on platinum was applied to modified and unmodified gold surfaces, and the results are shown in Figure 6.

The oscillation can be clearly observed on gold for both modified and unmodified surfaces. The frequency and amplitude of the oscilla-

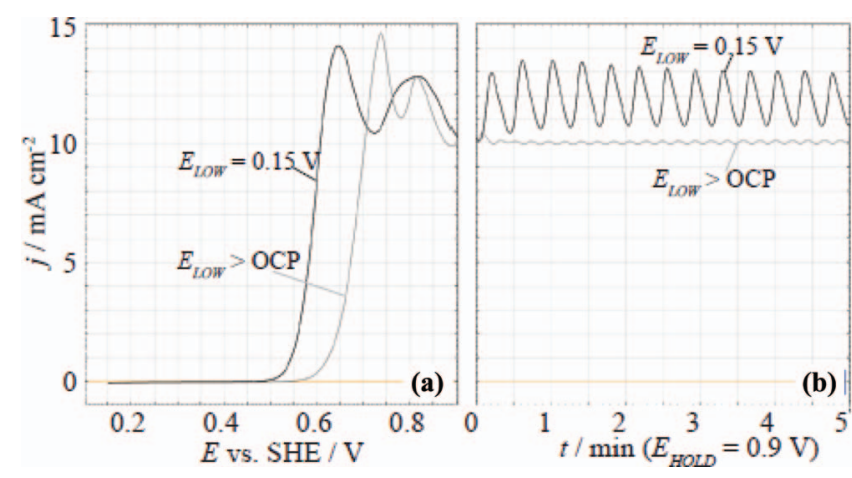

Figure 6. Oscillation observed on gold for unmodified and sulfur modified surface. (a) Potential sweep and (b) potential holding at $0.9 \mathrm{~V}$.

tions are summarized in Table I, where they are compared to values determined for a sulfur modified platinum electrode. A low frequency, large amplitude oscillation can be seen for sulfur modified gold, while values for the unmodified gold are more comparable to the response on activated platinum. Sulfur modification on gold has been shown to have only a small effect on onset and peak potentials, although the oscillation amplitude is clearly enhanced. Observation of the oscillation on unmodified gold suggests it is not in fact caused by the sulfur layer adsorbed prior to oxidation. Therefore, the oscillation is specific to the substrate only as a result of the active oxidation mechanism in this potential region.

Investigation of in-situ mass change on platinum and gold.- Oxidation on platinum and gold is significantly different. This has been discussed in terms of the different affinity of the substrate for sulfur dioxide adsorption. ${ }^{3}$ The EQCM is an excellent tool for monitoring in-situ mass changes at an electrode surface during polarization, and has not previously been applied to this reaction.

Oxidation in the absence of sulfur dioxide (baseline processes).Figure 7 shows a cyclic voltammogram taken on platinum and gold electrodes for both the current and mass change. The well known hysteresis of oxide formation on platinum is clearly demonstrated with the mass increasing gradually on the anodic scan, and stable until a potential of $0.9 \mathrm{~V}$ on the cathodic scan. A negative mass change is observed in the hydrogen adsorption region despite addition of hydrogen atoms to the electrode surface. This has long been observed and is accepted to result from the potential dependent desorption of sulfate and water species pre-adsorbed at higher potentials. ${ }^{18}$ An anodic sweep on gold shows a mass change prior to oxidation resulting from anion adsorption, followed by a much faster mass increase at higher potentials corresponding to oxide formation. ${ }^{14}$ The oxide is then reduced and anion desorption occurs, resulting in a return to the original mass at the electrode surface. Underpotential adsorption and desorption of hydrogen was not observed on the gold electrode. ${ }^{14}$

To interpret EQCM results, relationships between the expected mass change and the corresponding charge can be useful. If a bare platinum electrode undergoing oxidation is considered, the following reaction can be used to describe surface oxidation in acidic conditions: ${ }^{14}$

$$
\mathrm{Pt}+\mathrm{H}_{2} \mathrm{O} \rightarrow \mathrm{PtO}+2 \mathrm{H}^{+}+2 \mathrm{e}^{-}
$$

Table I. Oscillation frequency and amplitude of gold and platinum for $E_{H O L D}=0.9 \mathrm{~V}$.

\begin{tabular}{lccc} 
Substrate & $\begin{array}{c}E_{\text {LOW }} \text { vs. SHE } \\
(\mathrm{V})\end{array}$ & $\begin{array}{c}\text { Amplitude } \\
\left(\mathrm{mA} \mathrm{cm}^{-2}\right)\end{array}$ & $\begin{array}{c}\text { Frequency } \\
(\mathrm{mHz})\end{array}$ \\
\hline $\mathrm{Au}$ & $>\mathrm{OCP}$ & 0.134 & 76.81 \\
$\mathrm{Au}$ & 0.15 & 2.480 & 43.83 \\
$\mathrm{Pt}$ & 0.2 & 0.426 & 64.39
\end{tabular}



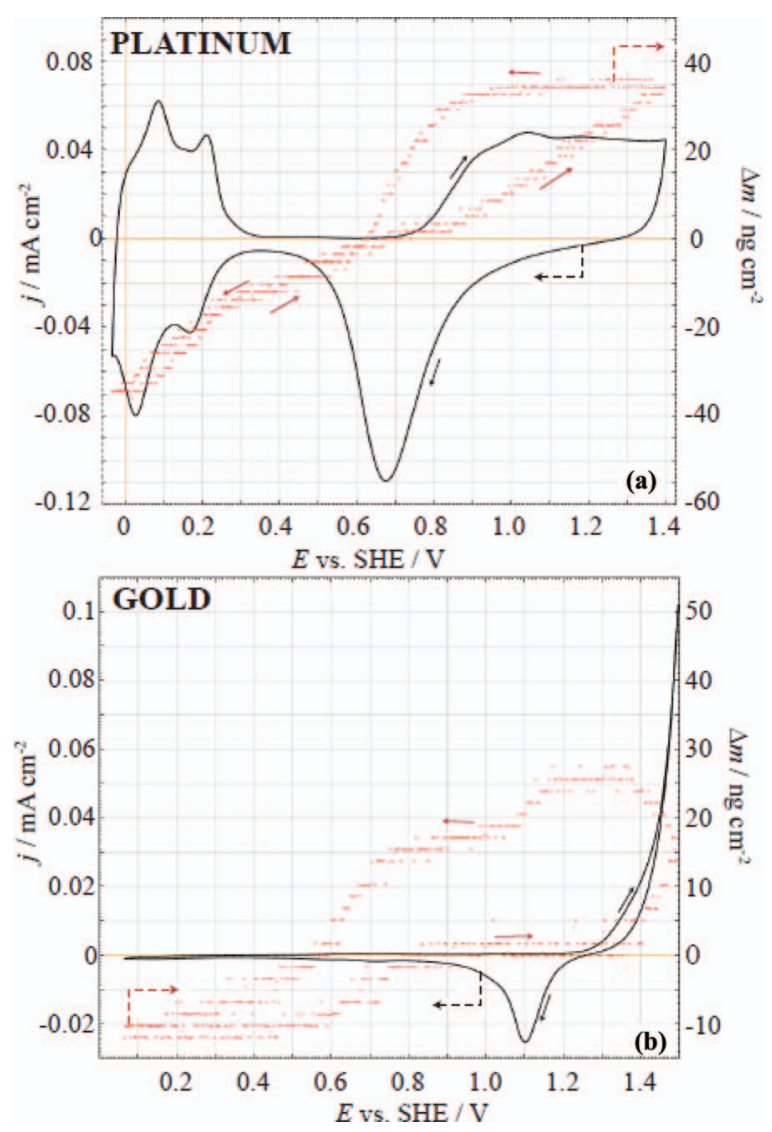

Figure 7. $1 \mathrm{M} \mathrm{H}_{2} \mathrm{SO}_{4}, 50 \mathrm{mV} \mathrm{s}^{-1}$, Current and mass response on platinum and gold electrodes during $\mathrm{CV}$ starting at $\mathrm{E}=0.8 \mathrm{~V}$ (starting mass zeroed at start potential).

Based on the stoichiometry we can determine an expected value for the mass change per unit charge. This is commonly expressed as:

$$
\Delta \mathrm{m}=\frac{\Delta \mathrm{QM}}{\mathrm{nF}}
$$

where $\Delta \mathrm{m}$ is the mass change ( $\mathrm{ng} \mathrm{cm}^{-2}$ ), $\Delta \mathrm{Q}$ is the charge density $\left(\mu \mathrm{C} \mathrm{cm}^{-2}\right), \mathrm{M}$ is the molar mass of the adsorbed species $\left(\mathrm{g} \mathrm{mol}^{-1}\right)$ after the transfer of $\mathrm{n}$ electrons, and $\mathrm{F}$ is Faraday's constant. ${ }^{18}$ The

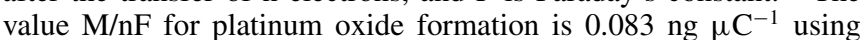
Eqn. 9. The experimental $\mathrm{M} / \mathrm{nF}$ value can be determined from the slope of a charge density versus mass change plot over the potential region of interest in a cyclic scan. Figure 8 shows this analysis for the positive sweep in Figure $7 \mathrm{a}$ from $0.4 \mathrm{~V}$ to $1.4 \mathrm{~V}$ where oxide

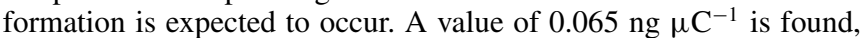
which is close to theoretical value. The difference is likely to be a result of potential dependent anion desorption in the oxide region, as previously noted in the literature. ${ }^{18}$

Oxidation of sulfur dioxide on platinum.-Sulfur Dioxide Addition at the Open Circuit Potential.-Specific adsorption of anions and water molecules to both platinum and gold electrodes has been widely investigated, ${ }^{18-22}$ and the EQCM has been found to be particularly useful for quantifying this adsorption. Anion adsorption on platinum has been confirmed to be potential dependent with the adsorption of $\mathrm{HSO}_{4}{ }^{-}$expected to occur between $0.40-1.40 \mathrm{~V}$, reaching a maximum at $0.8 \mathrm{~V} \cdot{ }^{20}$ Water adsorption also occurs during hydrogen desorption between $0.05-0.40 \mathrm{~V}$. The observed mass changes in these regions were analyzed by Santos et al. ${ }^{18}$

The potential region investigated in the current work for sulfur dioxide adsorption spans hydrogen desorption and anion adsorption potentials. Since more concentrated sulfuric acid solutions were used in this work than in the literature ${ }^{18}$ analysis of expected sulfate ad-

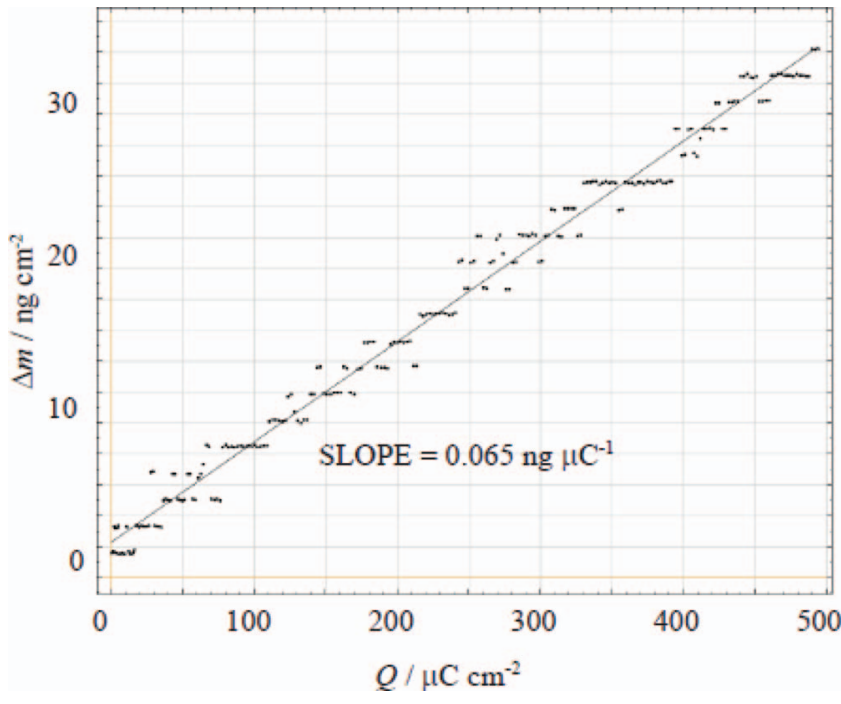

Figure 8. Mass change interpretation of oxide formation for the $0.8<\mathrm{E}$ $<1.4 \mathrm{~V}$ potential range (positive sweep) calculated using results in Figure 7.

sorption has been carried out in both $1 \mathrm{M}$ and $4 \mathrm{M}$ sulfuric acid. These results (Figure 9) show two linear regions corresponding to different potential regions including water adsorption (shallow slope) and anion adsorption (steep slope), although there has been some debate regarding the potential limits with respect to water adsorption and desorption. ${ }^{19}$

The slope of the data in Figure 9 compare well with the literature for the $1 \mathrm{M} \mathrm{H}_{2} \mathrm{SO}_{4}$ case. An $\mathrm{M} / \mathrm{n}$ value of $135 \mathrm{~g} \mathrm{~mol}^{-1}$ was found by Santos et al. in $0.1 \mathrm{M} \mathrm{H}_{2} \mathrm{SO}_{4}$, compared to our calculated value of $138 \mathrm{~g} \mathrm{~mol}^{-1}$ in $1 \mathrm{M} \mathrm{H}_{2} \mathrm{SO}_{4}$. In the analysis done by Santos et al., ${ }^{18}$ the value of $135 \mathrm{~g} \mathrm{~mol}^{-1}$ was related to the adsorption of a hydrated sulfate species $\left(\mathrm{HSO}_{4}{ }^{-} \cdot 2 \mathrm{H}_{2} \mathrm{O}\right)$ which will also be assumed in this analysis. The adsorption of water molecules to monolayer coverage $\left(40 \mathrm{ng} \mathrm{cm}^{-2}\right)$ was not observed for either acid concentration - a particularly small coverage was observed in $4 \mathrm{M} \mathrm{H}_{2} \mathrm{SO}_{4}$ $\left(\sim 12 \mathrm{ng} \mathrm{cm}^{-2}\right)$. It is therefore expected that water species will

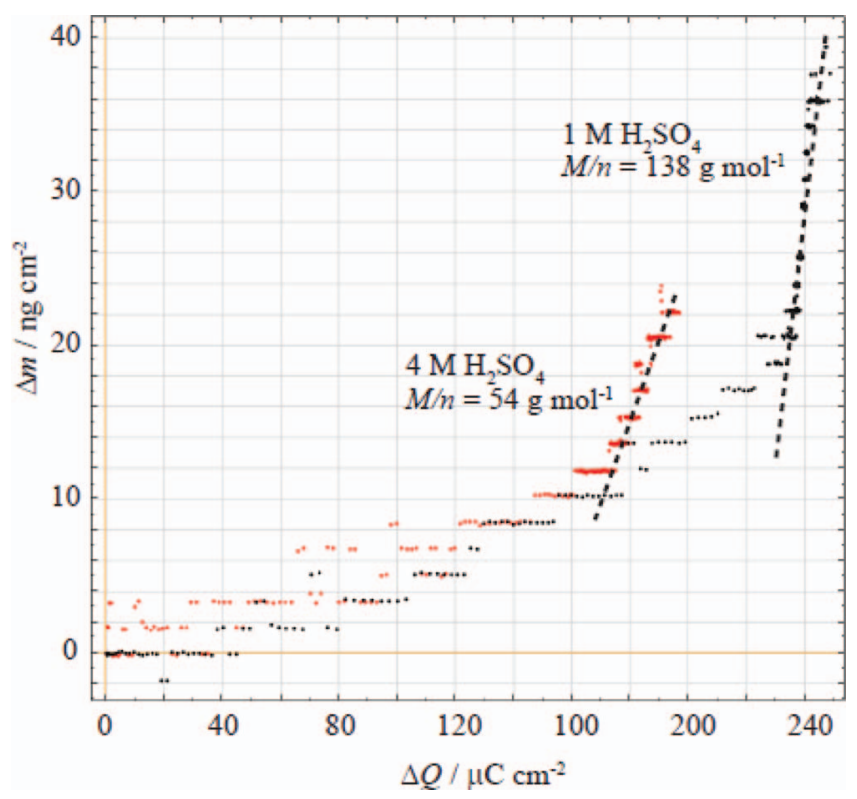

Figure 9. Mass gain on a platinum EQCM electrode in the hydrogen desorption region (forward sweep) from 0 to $0.8 \mathrm{~V}$ shown as a function of charge passed for 1 and $4 \mathrm{M} \mathrm{H}_{2} \mathrm{SO}_{4}$. 
continue to adsorb into the anion adsorption region for the acids used here. The observed mass change for $4 \mathrm{M} \mathrm{H}_{2} \mathrm{SO}_{4}\left(54 \mathrm{~g} \mathrm{~mol}^{-1}\right)$ is not equivalent to even the dehydrated sulfate molecule $\left(96 \mathrm{~g} \mathrm{~mol}^{-1}\right)$, and the continuing adsorption of water species in this region must therefore account for this difference. Sulfuric acid solutions more concentrated than $0.5 \mathrm{M}$ have not been investigated in the literature, although a weak correlation between increased coverage and bulk $\mathrm{HSO}_{4}{ }^{-}$concentration was noted for low concentrations up to $10 \mathrm{mM} .{ }^{20}$ Increased $\mathrm{HSO}_{4}{ }^{-}$adsorption in more concentrated acid solutions is therefore expected.

We can also estimate the expected anion coverage $\left(\theta_{\mathrm{HSO}_{4}^{-}}\right)$as a function of the potential by division of the mass change attributed to anion adsorption by the theoretical mass of a monolayer coverage of adsorbate; i.e.,

$$
\theta_{\mathrm{HSO}_{4}^{-}}=\frac{\Delta m_{\mathrm{HSO}_{4}^{-}}}{\frac{\mathrm{M}}{\mathrm{n}} \times 2.18 \times 10^{-9}}
$$

The result is $\sim 6 \%$ coverage for anion adsorption in $1 \mathrm{M} \mathrm{H}_{2} \mathrm{SO}_{4}$, a value very close to the $7 \%$ coverage specified in the literature for $0.1 \mathrm{M} \mathrm{H}_{2} \mathrm{SO}_{4}{ }^{18}$ This is important to estimate in order to determine the balance of species on sulfur dioxide addition. Adsorption of $\mathrm{SO}_{2}$ has been investigated at the open circuit potential ( $\sim 0.5 \mathrm{~V}$ vs. SHE). For this potential an estimate of $5 \%$ coverage (hydrated, $\mathrm{HSO}_{4}{ }^{-} .2 \mathrm{H}_{2} \mathrm{O}$ ) is reasonable, with the remaining surface assumed to be covered with adsorbed water molecules. This equates to a mass of $52 \mathrm{ng} \mathrm{cm}^{-2}$ at the electrode surface for $1 \mathrm{M} \mathrm{H}_{2} \mathrm{SO}_{4}$. Coverage in the case of $4 \mathrm{M}$ $\mathrm{H}_{2} \mathrm{SO}_{4}$ is more difficult to estimate since the molar mass of the species adsorbed could not be determined (to be discussed). The mass change at the electrode surface was monitored as a function of time, and sulfur dioxide (in the form of $\mathrm{SO}_{3}{ }^{2-}$ ) was added after $60 \mathrm{~s}$ wait to the purged sulfuric acid (the solution was stirred during addition time only). The mass response for several scenarios is shown in Figure 10.

From this figure both sulfuric acid and sulfur dioxide concentrations affect the overall mass change at a platinum electrode surface at the open circuit potential. Assuming an initial mass of $52 \mathrm{ng} \mathrm{cm}^{-2}$ for $1 \mathrm{M} \mathrm{H}_{2} \mathrm{SO}_{4}$, as discussed above, the overall mass change on addition of sulfur dioxide is $81 \mathrm{ng} \mathrm{cm}^{-2}$ for $10 \mathrm{mM} \mathrm{SO}_{2}$ and $110 \mathrm{ng} \mathrm{cm}^{-2}$ for $100 \mathrm{mM} \mathrm{SO}_{2}$. If we assume this mass change is a result of the replacement of the $\mathrm{SO}_{4}{ }^{2-} / \mathrm{H}_{2} \mathrm{O}$ layer with $\mathrm{SO}_{2}$, and $\mathrm{SO}_{4}{ }^{2-}$ is preferentially displaced over $\mathrm{H}_{2} \mathrm{O}$, the expected sulfur dioxide coverage is calculated as $\left.\theta_{\mathrm{SO}_{2}}=0.58(10 \mathrm{mM} \mathrm{SO})_{2}\right)$ and $\theta_{\mathrm{SO}_{2}}=0.79(100 \mathrm{mM}$ $\mathrm{SO}_{2}$ ). This suggests a saturation coverage of $\theta_{\mathrm{SO}_{2}}=0.79$ since we would expect a larger increase in coverage for a direct concentration dependence (i.e., ten times the coverage observed in $10 \mathrm{mM}$ solution). In fact sulfur coverage from reduction of adsorbed sulfur dioxide on a platinum electrode has previously been observed to reach a maximum of 0.88 , with full coverage only possible using a 'double reduction' method. ${ }^{23}$ This was thought to be required due to steric effects of adsorbed sulfur dioxide limiting the maximum electrode coverage.

Results are more difficult to interpret for a $4 \mathrm{M} \mathrm{H}_{2} \mathrm{SO}_{4}$ since the pre-adsorbed layer could not be realistically estimated. It is clear from Figure 10 that mass replacement occurs on the electrode surface since an overall mass loss occurs, and several scenarios can therefore be envisaged. Scenarios considered include complete displacement of adsorbed $\mathrm{SO}_{4}{ }^{2-}$ with no $\mathrm{SO}_{2}$ replacement (initial coverage calculated as $\theta_{\mathrm{HSO}_{4}^{-}}=0.42$ ), complete coverage of electrode with sulfate species prior to sulfur dioxide addition, or an equivalent sulfur dioxide adsorption as seen in $1 \mathrm{M} \mathrm{H}_{2} \mathrm{SO}_{4}$ solution (initial coverage of $\theta_{\mathrm{HSO}_{4}^{-}}=0.86$ ). The actual coverage prior to oxidation is therefore likely to be within $0.42<\theta_{\mathrm{HSO}_{4}^{-}}<0.86$ with an inferred final sulfur dioxide coverage of $\theta_{\mathrm{SO}_{2}}<0.79$. Sulfate adsorption in more concentrated acid solutions therefore results in higher initial sulfate coverage and lower sulfur dioxide uptake, resulting in a lower overall sulfur dioxide coverage.

Mass change on platinum during sulfur dioxide reduction.-Following introduction of sulfur dioxide to the electrolyte, sulfur modification of the platinum EQCM disk was carried out. A similar analysis to that described for oxide formation and sulfate adsorption (Figure 8)
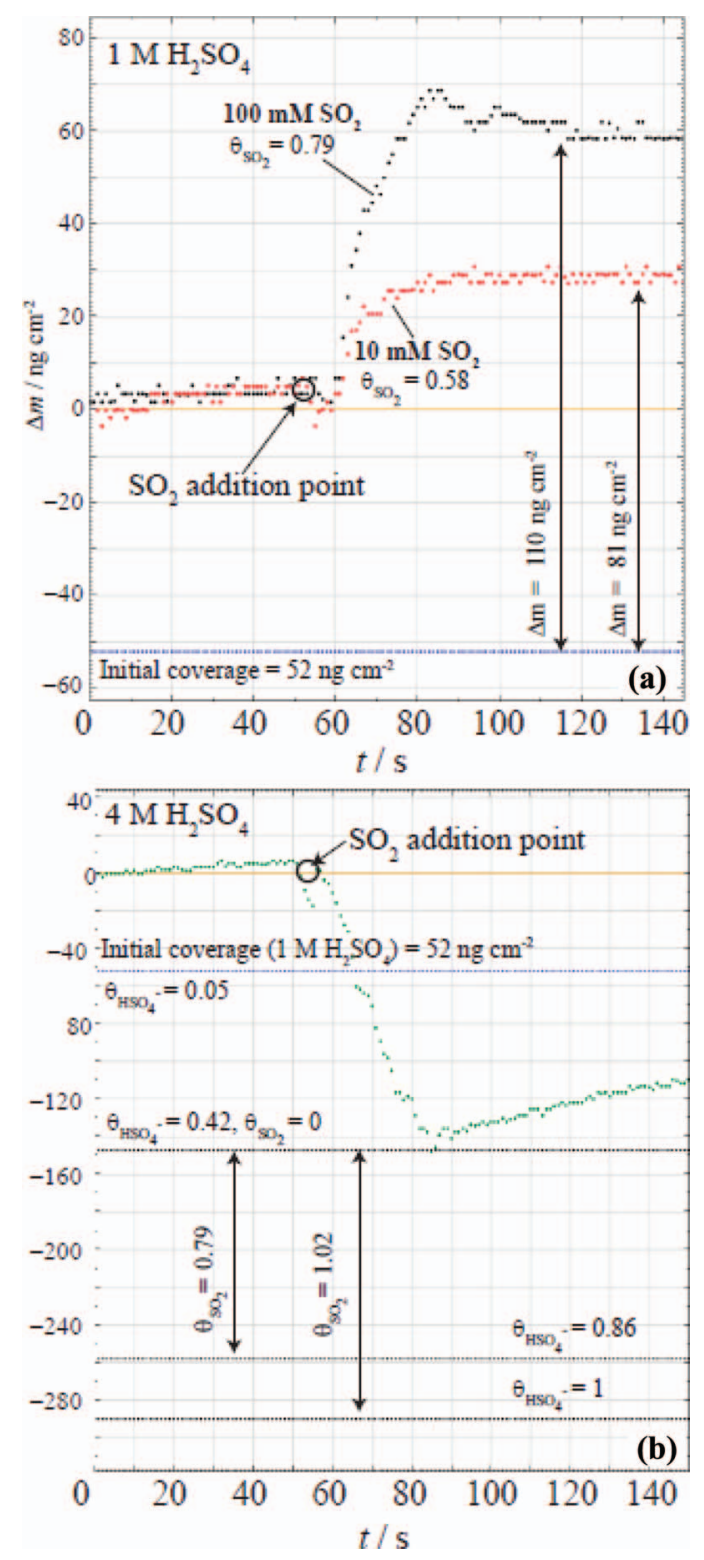

Figure 10. Mass change at the platinum electrode surface as a function of time at OCP. Addition point of sulfur dioxide indicated in figure. (a) Comparison in $1 \mathrm{M} \mathrm{H}_{2} \mathrm{SO}_{4}$ for 10 and $100 \mathrm{mM}$ final $\mathrm{SO}_{2}$ concentration. (b) Results in $4 \mathrm{M}$ $\mathrm{H}_{2} \mathrm{SO}_{4}$ for $100 \mathrm{mM} \mathrm{SO}_{2}$ concentration.

has been used to examine the sulfur layer formed, and therefore the state of the electrode surface prior to oxidation. It was calculated above that a sub-monolayer of sulfur dioxide was already adsorbed at the electrode surface prior to oxidation. Therefore, both adsorbed and bulk sulfur dioxide are expected to be reduced and contribute to the mass change. These reactions would result in an overall mass loss or gain, respectively, as indicated in Figure 11.

An overall mass gain was observed for $1 \mathrm{M} \mathrm{H}_{2} \mathrm{SO}_{4}$ with both 10 and $100 \mathrm{mM} \mathrm{SO}_{2}$ concentrations. For $100 \mathrm{mM} \mathrm{SO}_{2}$, if all adsorbed sulfur dioxide $\left(\theta_{\mathrm{SO}_{2}}=0.79\right)$ was converted to adsorbed sulfur (assuming no $\mathrm{H}_{2} \mathrm{O}$ is removed from the surface during reduction), a mass loss of 55 $\mathrm{ng} \mathrm{cm}{ }^{-2}$ would be observed. Since an overall mass gain was observed $\left(\Delta \mathrm{m}_{\max }=14 \mathrm{ng} \mathrm{cm}^{-2}\right), 69 \mathrm{ng} \mathrm{cm}^{-2}$ of sulfur must be adsorbed as a result of sulfur dioxide reduction. An overall sulfur coverage of $\theta_{\mathrm{S}}=1.78$ can then be calculated with $\sim 44 \%$ of this resulting from reduction of the previously adsorbed sulfur dioxide species. The same calculation can be repeated for the $10 \mathrm{mM} \mathrm{SO}_{2}$ case giving $\theta_{\mathrm{S}}=1.20$ with $\sim 48 \%$ resulting from the adsorbed layer. Less sulfur is formed, 


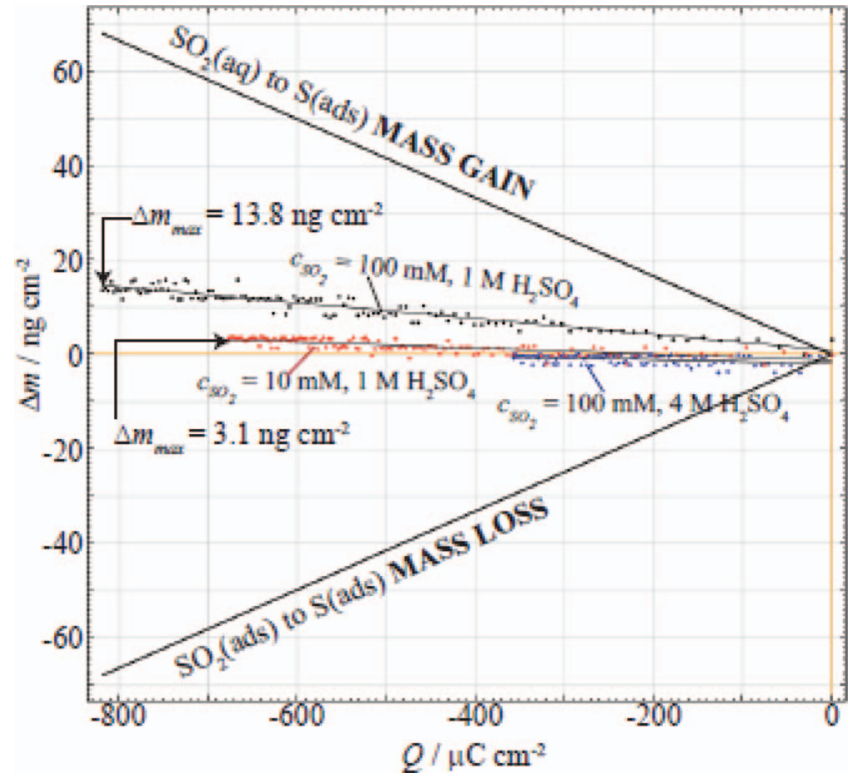

Figure 11. Mass change and charge density observed during reduction for different solution compositions, concentrations indicated in figure. $\mathrm{E}_{\text {low }}$ $=0.15 \mathrm{~V}, \mathrm{t}=2$ minutes.

although a larger proportion results from the pre-adsorbed sulfur layer. This reflects the decreased availability of solution sulfur dioxide at the electrode surface as result of the lower concentration solution.

No mass change is observed in the $4 \mathrm{M} \mathrm{H}_{2} \mathrm{SO}_{4}$ solution; however, once again mass balance at the electrode surface is emphasized, considering the substantial reduction charge observed. An even contribution from adsorbed and solution sulfur dioxide is therefore expected in this case with increased sulfur resulting from adsorbed sulfur dioxide (50\% compared to only $44 \%$ in $1 \mathrm{M} \mathrm{H}_{2} \mathrm{SO}_{4}$ ). This is most likely as a result of the decreased activity of sulfur dioxide in concentrated acid solutions (cf. Figure 4).

Voltammetric behavior.-The mass change was monitored during a full cyclic sweep immediately following electrode pre-treatment for catalytic activation of the electrode. Figure $12 \mathrm{~b}$ shows the theoretical mass change calculated from the overall charge passed for the bulk oxidation of sulfur dioxide in Figure 12a. The expected mass change for the oxidation of alternately bulk and adsorbed sulfur dioxide to
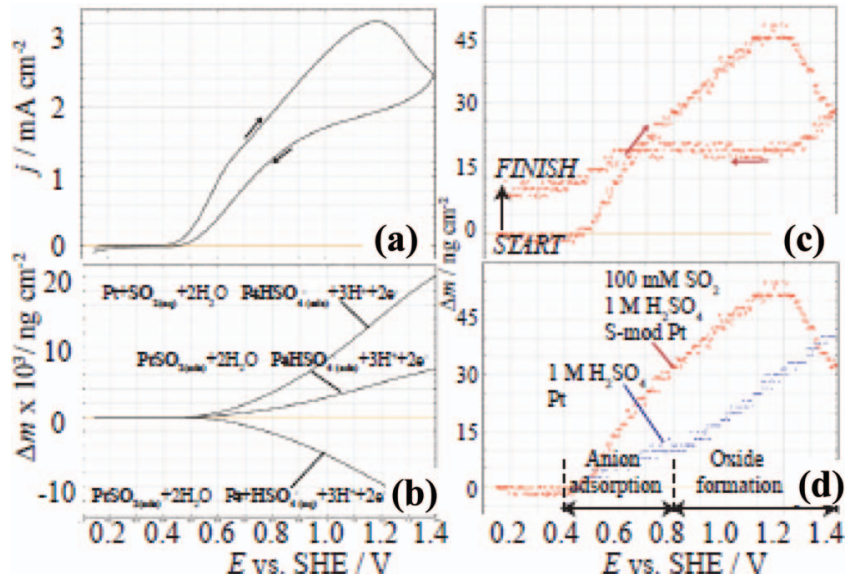

Figure 12. Voltammetric and EQCM behavior on a platinum electrode: 1 $\mathrm{M} \mathrm{H}_{2} \mathrm{SO}_{4}, 100 \mathrm{mM} \mathrm{SO} 2,50 \mathrm{mV} \mathrm{s}^{-1}$ initial scan following pre-treatment (a) Current density; (b) theoretical mass change based on charge passed during anodic scan in (a); (c) mass change during $\mathrm{CV}$; (d) comparison of mass change in $1 \mathrm{M} \mathrm{H}_{2} \mathrm{SO}_{4}$ with and without $100 \mathrm{mM} \mathrm{SO}_{2}$. form either bulk or adsorbed sulfate, respectively, has been calculated as indicated. These mass changes are large, as would be expected for the current density observed. In fact the real mass change at the electrode surface is significantly smaller, and is seen in Figure $12 \mathrm{c}$ to follow the shape of the oxidation very closely, including a decrease in mass at high potentials and a knee at low potentials. The overall mass change is smaller than a monolayer of both sulfate and sulfur dioxide, and the bulk effects shown in Figure $12 \mathrm{~b}$ are not observed. This is clear evidence to negate a previous suggestion of the buildup of product species at the electrode surface leading to inhibition of the oxidation reaction at high potentials. ${ }^{5}$

If we compare the observed mass change during oxidation with the mass change observed for oxide formation, as shown in Figure 12d, it can be seen that the overall gain in the presence of sulfur dioxide is higher than that seen for an oxide layer, and also increases at a faster rate (mainly at lower potentials). Oxide layer formation appears to be altered or inhibited, probably due to the existing sulfur layer on the platinum electrode surface.

Mass changes at the EQCM electrode surface in the $10 \mathrm{mM} \mathrm{SO}_{2}$ $+4 \mathrm{M} \mathrm{H}_{2} \mathrm{SO}_{4}$ solution are shown in Figure 13b. The curves vary significantly depending on the solution conditions, although in each case the mass increases during oxidation were less than the equivalent of a monolayer of sulfur dioxide $\left(116 \mathrm{ng} \mathrm{cm}^{-2}\right)$. The mass change at the electrode surface for both 10 and $100 \mathrm{mM} \mathrm{SO}_{2}$ solutions follows the observed current density trends, including a peak in the observed mass change at low potentials in $10 \mathrm{mM} \mathrm{SO}_{2}$ solutions. For a $10 \mathrm{mM} \mathrm{SO}_{2}$ concentration, we can further see a mass increase in the
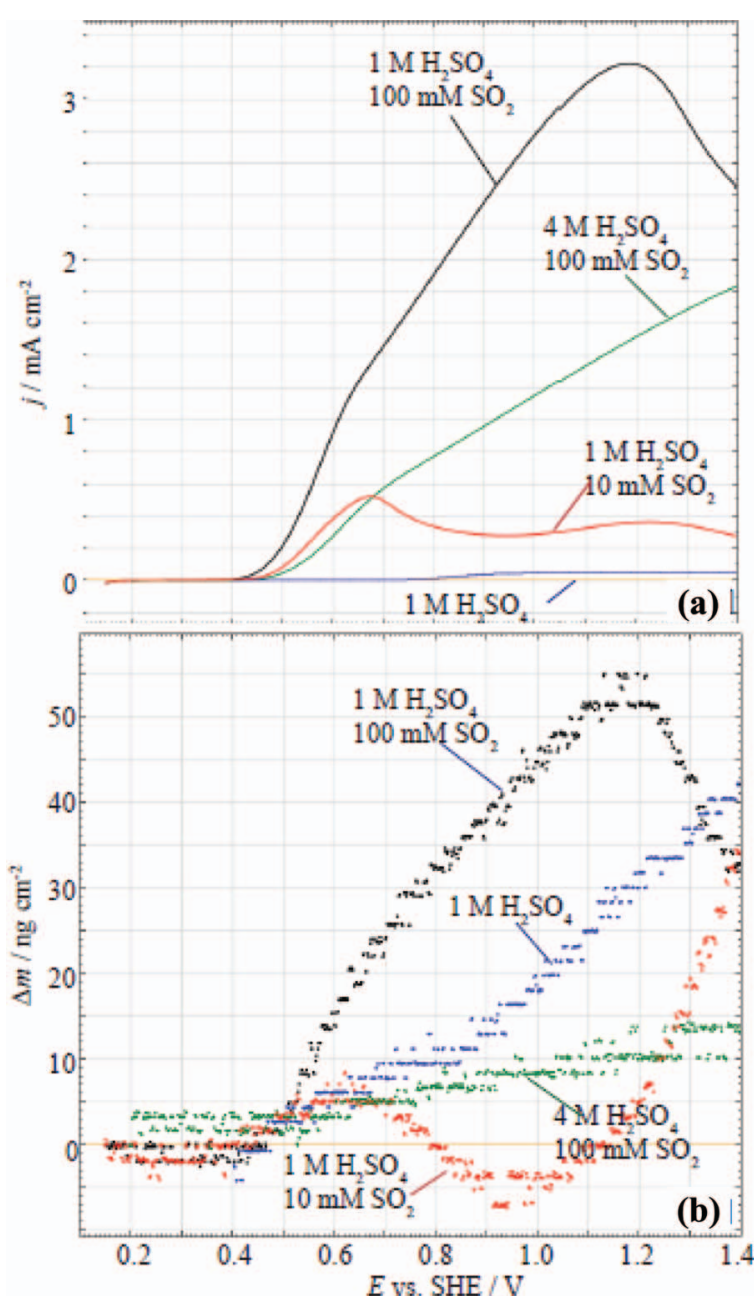

Figure 13. Performance of sulfur modified platinum electrode in different composition solutions. (a) Voltammetric response and (b) mass change. 


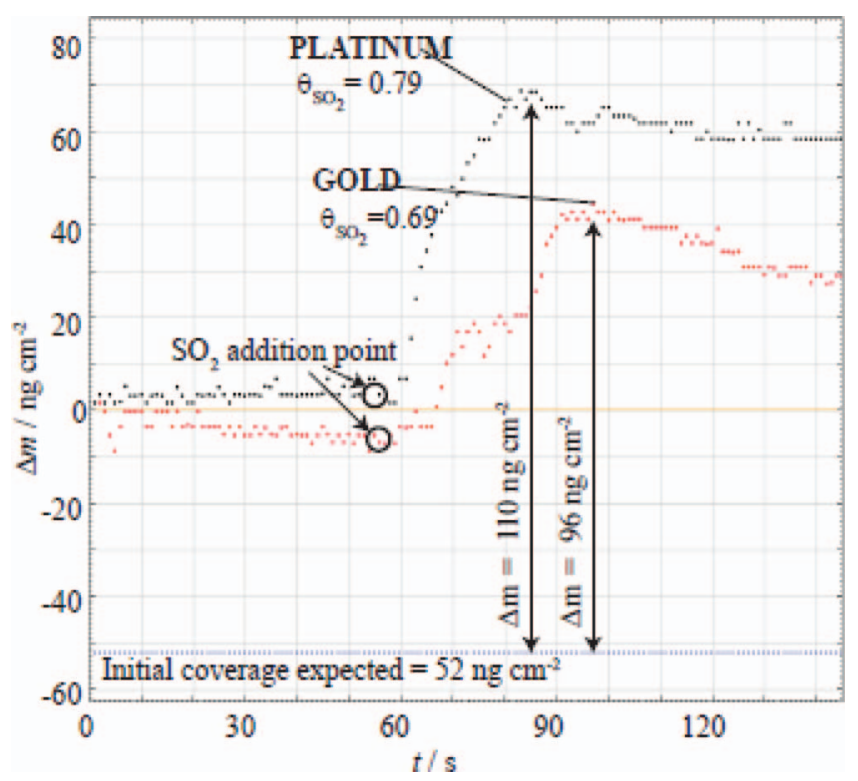

Figure 14. Mass change at the electrode surface as a function of time at both platinum and gold electrode surfaces. $1 \mathrm{M} \mathrm{H}_{2} \mathrm{SO}_{4}, 100 \mathrm{mM} \mathrm{SO}$ final concentration; $\mathrm{SO}_{2}$ addition point indicated in figure.

oxide formation region, although this shape and rate of mass increase is different to that seen in the absence of sulfur dioxide. For a $4 \mathrm{M}$ $\mathrm{H}_{2} \mathrm{SO}_{4}$ solution, the mass change is much smaller than in the case of the $1 \mathrm{M}$ solution despite identical sulfur dioxide concentrations.

Comparative mass changes on gold and platinum.- It was seen in Figure 10 that the open circuit response of the system to sulfur dioxide addition on platinum indicates a mass gain approximating a sulfur dioxide coverage of $\theta_{\mathrm{SO}_{2}}=0.79$. This value was determined using an approximation for the initial sulfate adsorption to the platinum surface calculated from the mass change in $1 \mathrm{M} \mathrm{H}_{2} \mathrm{SO}_{4}$ in the absence of sulfur dioxide. Sulfate layer coverage on gold can be reasonably assumed to be very similar to platinum according to literature comparisons, ${ }^{21}$ therefore the value of $52 \mathrm{ng} \mathrm{cm}{ }^{-2}$ has been taken as the mass of the sulfate layer present prior to sulfur dioxide addition on gold. A comparison of the response on platinum and gold is shown in Figure 14.

A similar mass change response was observed on a gold electrode (compared to platinum) after sulfur dioxide addition, although the change is of smaller magnitude and the initial mass gain is followed by a loss. Assuming an equivalent sulfate layer, this implies that a smaller overall sulfur dioxide coverage is attained, initially in this case with $\theta_{\mathrm{SO}_{2}}=0.69$. An overall negative mass change of only $5 \mathrm{ng} \mathrm{cm}^{-2}$ occurred after potential holding. If adsorbed sulfur dioxide reduction alone contributed to this loss, a sulfur layer equating to only $\theta_{\mathrm{S}}=0.07$ would have been formed, with a large proportion of adsorbed sulfur dioxide apparently remaining at the electrode surface.

The voltammetric response for platinum and gold is compared in Figure 15a. While onset of the mass change coincides with the start of sulfur dioxide oxidation for both gold and platinum, it can be seen that this response is opposite for the different metals (Figure 15b). Unlike platinum, the response on gold decreases consistently until high potentials where a slight increase in mass at the gold surface can be observed. This does not appear to coincide with a specific current response feature; however, this is the region where gold surface oxidation becomes substantial, ${ }^{18}$ inhibiting oxidation, and the mass change is likely related. For the cathodic scan on gold, mass is regained at the electrode surface and returns close to its original state, showing a small overall mass change during oxidation - similar to the behavior on platinum.

Interpretation of mass change results.- Mass changes at the electrode surface have not previously been investigated for this reaction,
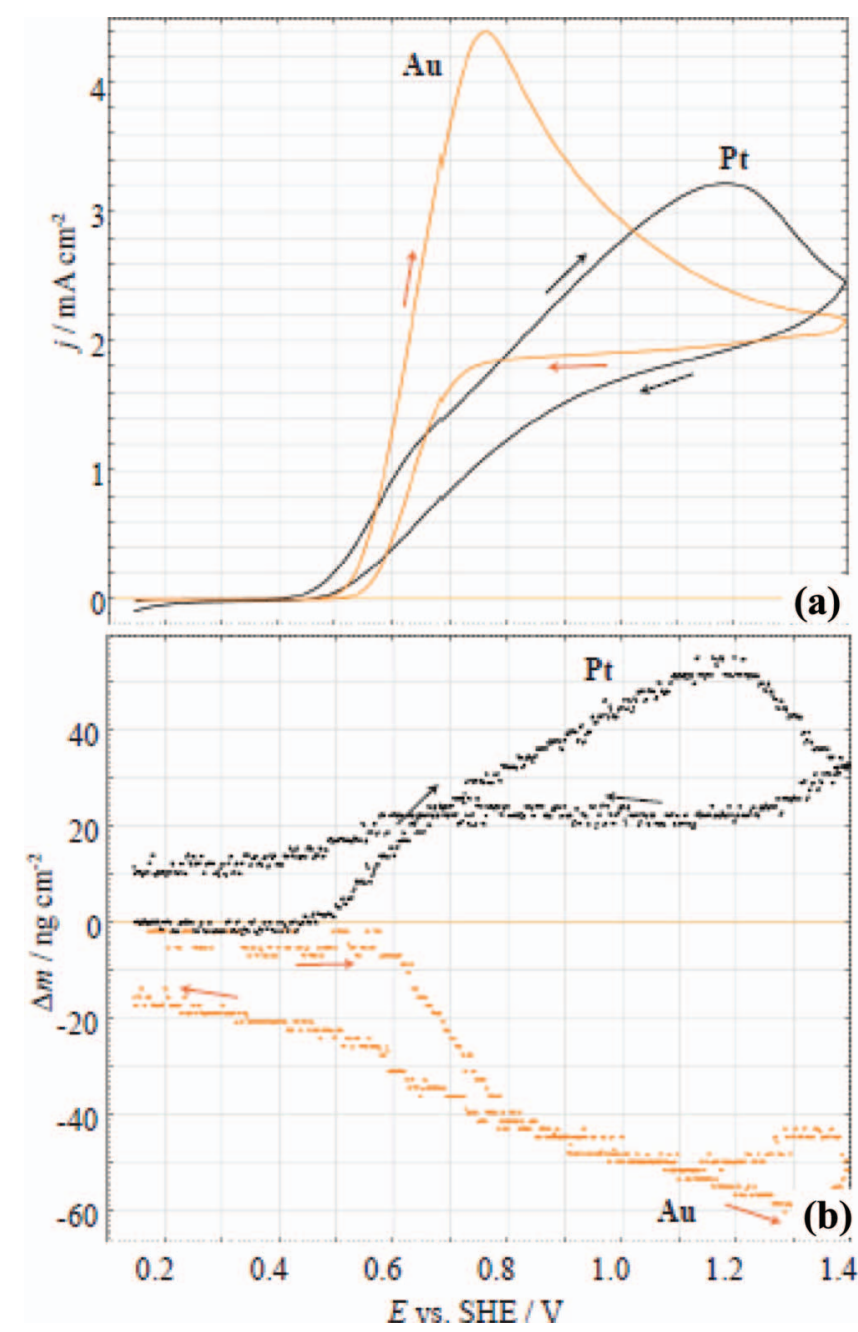

Figure 15. Comparative behavior of platinum and gold EQCM electrode. (a) Current response and (b) mass change at EQCM platinum and gold electrodes during sulfur dioxide oxidation. Scan direction indicated in figure. $1 \mathrm{M}$ $\mathrm{H}_{2} \mathrm{SO}_{4}, 100 \mathrm{mM} \mathrm{SO}_{2}, \mathrm{E}_{\text {low }}=0.15 \mathrm{~V}, 50 \mathrm{mV} \mathrm{s}^{-1}$.

and give crucial information regarding the oxidation mechanism if they can be interpreted correctly. In order to understand these mass changes, a general mechanism involving diffusion processes and adsorption of reactants and products can be considered, as outlined in Figure 16.

Five key steps are shown here including:

(1) Diffusion of reactants to the electrode surface.

(2) Adsorption of the reactants to the electrode surface.

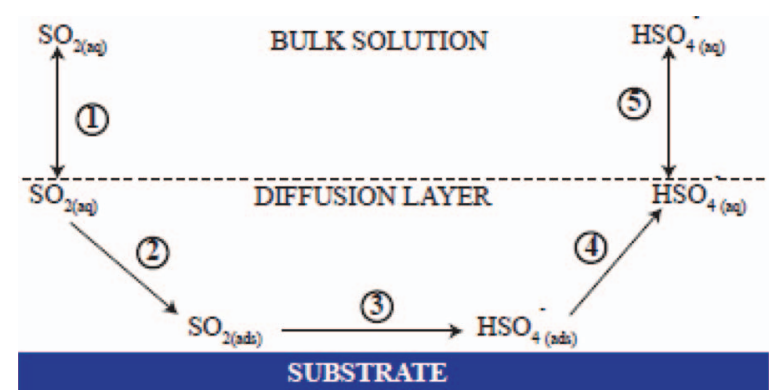

Figure 16. Outline of key processes occurring during oxidation of aqueous sulfur dioxide. 
(3) Oxidation of adsorbed reactants at the electrode surface.

(4) Desorption of reaction products.

(5) Diffusion of products into the bulk solution.

These processes control the mass change at the electrode surface depending on the rate determining step (RDS) for overall charge transfer. These steps have been simplified for the sake of discussion, and it is expected that other elementary reaction steps are also involved including the formation of a dithionate intermediate in Step (3), as outlined in Reference. ${ }^{12}$

Consideration of Figure 16 reveals that no net mass change would occur over the course of the oxidation if Steps (1), (2) or (5) were the RDS. Although adsorption is involved in Step (2), once adsorbed the oxidation occurs quickly followed by equally fast desorption of the product species. No build up of either reactants or products would be observed in this case.

A mass gain might be observed if Step (3) were the RDS since oxidation of sulfur dioxide would then be limiting. Fast adsorption of sulfur dioxide followed by slow oxidation could therefore lead to a build up of adsorbed sulfur dioxide at the electrode surface and a mass gain would be observed - presumably to a saturated coverage.

An increase in mass might also be observed if Step (4) were the RDS since sulfate species would build up due to their slow desorption. This effect would also be potential dependent due to the increased adsorption of the electronegative sulfate/bisulfate species present in solution, as observed in the absence of sulfur dioxide. ${ }^{18}$

Platinum.-The deposited mass was observed to increase on a sulfur modified platinum electrode over the course of an anodic scan, with the mass gain following the oxidation response closely for both 10 and $100 \mathrm{mM} \mathrm{SO}_{2}$ solutions. This indicates that the RDS is not Step (1), (2) or (5), as discussed above. Mixed control with kinetic limitations for a sulfur modified platinum electrode was indicated previously, confirming that limitation by diffusion (Step (1) as RDS) is unlikely.

If we consider Step (3) as the RDS, the amount of sulfur dioxide adsorbed to the electrode surface would be determined by the rate of oxidation. However for high oxidation rates the amount of adsorbed sulfur dioxide would be expected to decrease even if an excess is initially adsorbed. An opposite mass change response to that observed would therefore be expected, with mass build up as the oxidation rate slows, and mass loss as the rate increases. Alternatively, a mechanistic step within Step (3) may cause mass build up at the electrode surface; e.g., the formation and dissociation of dithionate. ${ }^{12}$ It is possible that slow dissociation of dithionate results in its build up at the electrode surface. This scenario shows similar limitations to Step (4) as the RDS involving the slow desorption of the product sulfate species. For a fast oxidation rate, a build up of sulfate/dithionate species would be expected considering the slow subsequent desorption and/or dissociation of these species. As the oxidation rate decreases, desorption or dissociation of built up species is enabled leading to an overall mass loss. The limiting desorption of sulfate would also explain inhibited behavior in more concentrated acids. A smaller mass gain is seen in $4 \mathrm{M} \mathrm{H}_{2} \mathrm{SO}_{4}$, as well as a decreased oxidation rate. This is likely to be due to the less favorable concentration gradient observed for more concentrated $\mathrm{H}_{2} \mathrm{SO}_{4}$ solutions, with strong limitation of the oxidation rate as a result of the slow subsequent desorption of product species. Comparing results in different acid concentrations suggests a balance of these limitations dependent on the acid concentration. In low concentrations, dissociation of dithionate is limiting since its dissociation is dependent on protonation, ${ }^{24}$ while in high acid concentrations the desorption of sulfate becomes limiting with faster dithionate dissociation allowed.

Gold.-A mass decrease was observed during sulfur dioxide oxidation on a gold substrate, with the majority of mass regained on cycling. A different RDS scenario is therefore in effect compared to platinum, since neither Step (2) or (3) would result in a mass loss. In fact, mass loss is not expected for any of the possible RDSs proposed here. However, it has been emphasized that the mass change observed using the EQCM is in fact a balance of species which is also dependent on the initial mass due to species adsorbed on the electrode surface prior to oxidation. Some sulfur dioxide is expected to be initially adsorbed onto the gold electrode surface since full reduction of adsorbed species does not occur on gold prior to oxidation. Oxidation of pre-adsorbed sulfur dioxide would occur quickly; however, exchange with new reactants results in an overall net decrease. As the oxidation rate decreases on the cathodic scan a build up of adsorbed sulfur dioxide would occur since the rate of removal is decreased. It is also possible that, due to a balance of species, the limitations of Steps (3) or (4) are overshadowed due to loss of pre-adsorbed species. However, diffusion limited behavior is observed for gold with a clear diffusion plateau in dilute solutions. Therefore, the RDS is most likely due to diffusion of reactants to the electrode surface (Step (1)).

\section{Conclusions}

The oxidation of sulfur dioxide on gold and platinum electrodes has been investigated and the key limitations of each have been proposed as, respectively, diffusion of reactants to the electrode surface, and oxidation of adsorbed reactants or desorption of products formed. It is proposed here that, despite large variations in behavior on gold and platinum, an essentially similar oxidation mechanism pathway is followed for an activated electrode. Although improved oxidation is enabled through use of a gold electrode or sulfur modification of a platinum electrode, high overpotentials are still observed. Oxidation on platinum and gold can only be slightly improved by surface modification. A more dramatic modification of the electrode surface is required if oxidation is to occur with decreased overpotential.

\section{Acknowledgments}

J. O'B acknowledge the CSIRO for the funding of a research internship.

\section{References}

1. J. Fu, M. Hou, C. Du, Z. G. Shao, and B. L. Yi, J. Power Sources, 187, 32 (2009).

2. G. J. Kolb, R. B. Diver, and N. Siegal, J. Solar Energy Eng., 129, 179 (2007).

3. J. A. O'Brien, J. T. Hinkley, and S. W. Donne, Electrochim. Acta, 55, 573 (2010).

4. H. R. Colon-Mercado, M. C. Elvington, and D. T. Hobbs, Close-out report for HyS Electrolyser component development work at Savannah River National Laboratory, in, Savannah River National Laboratory, Aiken, SC (2010).

5. J. A. O'Brien, J. T. Hinkley, and S. W. Donne, J. Electrochem. Soc., 157, F111 (2011).

6. A. J. Appleby and B. Pinchon, J. Electroanal. Chem., 95, 59 (1979).

7. C. Quijada, A. Rodes, J. L. Vazquez, J. M. Perez, and A. Aldaz, J. Electroanal. Chem., 398, 105 (1995).

8. E. T. Seo and D. T. Sawyer, Electrochim. Acta, 10, 239 (1965).

9. R. M. Spotnitz, J. A. Colucci, and S. H. Langer, Electrochim. Acta, 28, 1053 (1983).

10. A. J. Bard, R. Parsons, and J. Jordan, Standard Potentials in Aqueous Solutions, International Union of Pure and Applied Electrochemistry, New York (1985).

11. C. Quijada and J. L. Vazquez, Recent Research Developments in Electrochemistry, 3, 137 (2000).

12. J. A. O'Brien, J. T. Hinkley, and S. W. Donne, Electrochim. Acta, 56, 4224 (2011).

13. A. J. Bard and L. R. Faulkner, Electrochemical Methods: Fundamentals and Applications, John Wiley \& Sons Inc, New York (2001).

14. R. Woods, in Electroanalytical Chemistry: A Series of Advances, A. J. Bard Editor, p. 1, Marcel Dekker Inc, New York (1976)

15. Z. Samec and J. Weber, Electrochim. Acta, 20, 413 (1975)

16. W. M. Haynes, CRC Handbook of Chemistry and Physics (2011).

17. R. N. Adams, Electrochemistry at Solid Electrodes, Marcel Dekker, Inc., New York, p. 221 (1969).

18. M. Santos, D. Miwa, and S. Machado, Electrochem. Comm., 2, 692 (2000).

19. G. Inzelt, B. Berkes, and A. Kriston, Pure and Applied Chem., 83, 269 (2011).

20. A. Kolics and A. Wieckowski, J. Phys. Chem. C, 105, 2588 (2001).

21. H. Uchida, N. Ikeda, and M. Watanabe, J. Electroanal. Chem., 424, 5 (1997).

22. M. Watanabe, H. Uchida, and N. Ikeda, J. Electroanal. Chem., 380, 255 (1995).

23. C. Quijada and J. L. Vazquez, J. Electroanal. Chem., 414, 229 (1996).

24. G. Lente and I. Fabian, Inorg. Chem., 43, 4019 (2004). 